\title{
ОЦЕНКА ОГНЕСТОЙКОСТИ ЖЕЛЕЗОБЕТОННОЙ КОЛОННЫ ЭКСПЕРИМЕНТАЛЬНО-РАСЧЕТНЫМ МЕТОДОМ НА ОСНОВЕ ЕЕ ОГНЕВЫХ ИСПЫТАНИЙ
}

\author{
Д-р техн. наук С.В. Поздеев, В.К. Словинский, А.М. Омельченко, М.А. Кропива \\ ОЦІНКА ВОГНЕСТІЙКОСТІ ЗАЛІЗОБЕТОННОЇ КОЛОНИ \\ ЕКСПЕРИМЕНТАЛЬНО-РОЗРАХУНКОВИМ МЕТОДОМ НА ОСНОВІ П̈Ї \\ ВОГНЕВИХ ВИПРОБУВАНЬ
}

\section{Д-р техн. наук С.В. Поздсєв, В.К. Словінський, А.М. Омельченко, М.О. Кропива ESTIMATION OF FIRE-RESISTANCE OF REINFORCED CONCRETE COLUMN BY
EXPERIMENTAL-CALCULATION METHOD ON THE BASIS OF ITS FIRE TESTS}

Doct. of techn. sciences, associate professor S.V. Pozdeyev, V.K. Slovinskiy, A.M. Omelchenko, M.O. Kropyva

В статье рассмотрень вопросы реализачии экспериментально-расчетного метода оценки огнестойкости железобетонных колонн на основе их огневых испытаний без приложения механической нагрузки. Применяя разработанный комплекс прочедур для реализации разработанного метода получен предел огнестойкости железобетонной колонны. Показано, что разработанный экспериментально-расчетный метод является эффективным для определения пределов огнестойкости несущих железобетонных строительных конструкиий.

Ключевые слова: испьтание на огнестойкость, огневая печь, железобетонная колонна, экспериментально-расчетный метод, интерполяция, температурное поле.

У статті розглянуто питання реалізаиії експериментально-розрахункового методу оцінки вогнестійкості залізобетонних колон на основі їх вогневих випробувань без прикладання механічного навантаження. Застосовуючи розроблений комплекс процедур для реалізачії розробленого методу одержана межа вогнестійкості залізобетонної колони. Показано, щзо розроблений експериментально-розрахунковий метод є ефективним для визначення меж вогнестійкості несучих залізобетонних будівельних конструкиій.

Ключові слова: випробування на вогнестійкість, вогнева піч, залізобетонна колона, експериментально-розрахунковий метод, інтерполяція, температурне поле.

The questions of realization of experimental-calculation method of estimation of fireresistance of reinforced concrete columns on the base of their fire tests without the appendix of the mechanical loading are considered in this article. Applying the developed complex of procedures for realization of the developed method the limit of fire-resistance of reinforced concrete column is got. It is shown, that the developed experimental-calculation method is effective for determination of limits of fire-resistance of bearing reinforced concrete build constructions.

Keywords: test on a fire-resistance, fire stove, reinforced concrete column, experimentalcalculation method, interpolation, temperature field.

Введение. При реализации испытаний возникают определенные технические железобетонных колонн на огнестойкость сложности, которые заключаются в 
несоответствии условий закрепления и нагрузки колонны, реализуемой в установках для испытаний закреплению и нагрузкам в соответствующей конструкции, несоответствию габаритных размеров колонны-образца для испытаний тем же параметрам реальной колонны и т.д. Поэтому стандартами Украины для испытаний колонн на огнестойкость $[1,2]$ не запрещаются испытания без приложения механических нагрузок, но в то же время указанный стандарт не дает обоснованной методики определения предела огнестойкости железобетонных колонн на основе таких испытаний.

Анализ публикаций [4-6], касающихся расчетных методов проектирования железобетонных колонн для их соответствия требованиям противопожарных норм, показывает, что данные методы дают возможность комплексно учесть все перечисленные особенности, что делает перспективным их сочетание с экспериментальными методами.
Цель исследований заключается в разработке эффективного экспериментально-расчетного метода оценки огнестойкости железобетонных колонн на основе их огневых испытаний без приложения механической нагрузки.

Основной материал исследований. В работе [4] предложен метод, который основан на математической интерпретации результатов огневых испытаний железобетонных колонн без приложения механической нагрузки. Данными, подлежащими интерпретации, являются значения температур, измеренные во внутренних слоях колонн, подвергнутых огневому воздействию в соответствии со стандартным температурным режимом пожара. Реализация метода происходит по алгоритму, блок-схема которого показана на рис. 1.

Измерения температуры при испытаниях происходят при расположении термодатчиков в сечении согласно схеме на рис. 2.
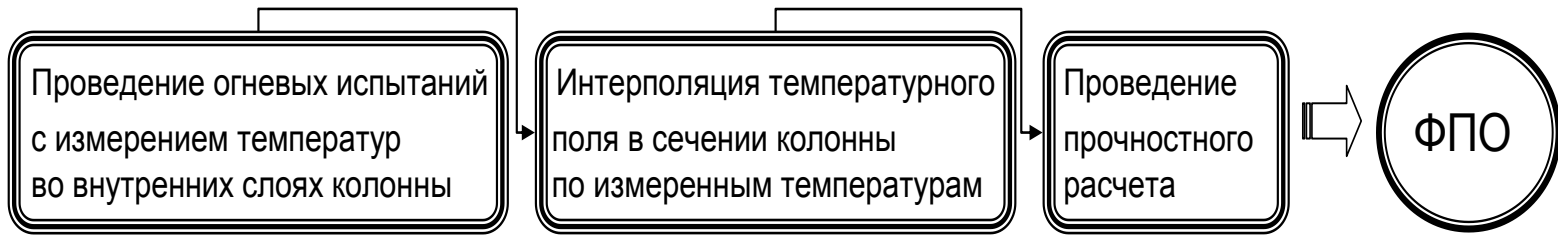

Рис. 1. Алгоритм реализации экспериментально-расчетного метода оценки огнестойкости железобетонных колонн

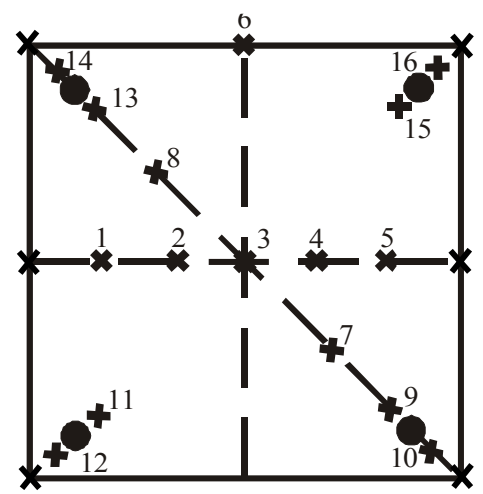

Рис. 2. Расположение термопар в сечениях железобетонной колонны (1-16 - номера контрольных точек в сечении) 
Наши исследования [4] показали, что эффективными методами интерполяции температурного поля являются методы, основанные на представлении температурных распределений по центральным горизонтали, вертикали и диагонали сечения параболами, которые могут быть в общем виде описаны выражением

$$
\left.T(i)\right|_{x \leq 0}=T_{0}+\left(T_{\max }-T_{0}\right)\left[\frac{i}{n}\right]^{q},
$$

где $T_{0}-$ минимальная температура, ${ }^{\circ} \mathrm{C}$; $T_{\max }$ - максимальная температура, ${ }^{\circ} \mathrm{C}$; $i$ - номер контрольной точки в плоскости сечения; $n$ - количество контрольных точек; $q$ - показатель степени параболы.

Проведение интерполяции может быть осуществлено тремя способами. Интерполяцию по первому способу предлагается проводить по аппроксимации линий, образованных фронтальными сечениями поверхности температурного поля, параболическими зависимости. По второму способу интерполяция осуществляется с использованием аппроксимации образующих поверхности температурного распределения параболическими зависимостями. Третий способ заключается в аппроксимации линий изотерм афинными кривыми и их построении в каждой точке дискретизированного сечения по зависимостям, определяемым выражением

$$
y(x)=q\left(1-\left(\frac{x}{q}\right)^{p}\right)^{1 / p},
$$

где $p$ и $q$ - коэффициенты, подлежащие определению при приближении поверхности распределения температур.

Задача приближения поверхности распределения температур решается путем минимизации среднеквадратической невязки.

Для изучения эффективности методов интерполяции были проведены огневые испытания двух железобетонных колонн $500 \times 500 \times 3000$ из тяжелого бетона на гранитном заполнителе в огневой печи. Схема и общий вид испытательной установки приведены на рис. 3 и 4.

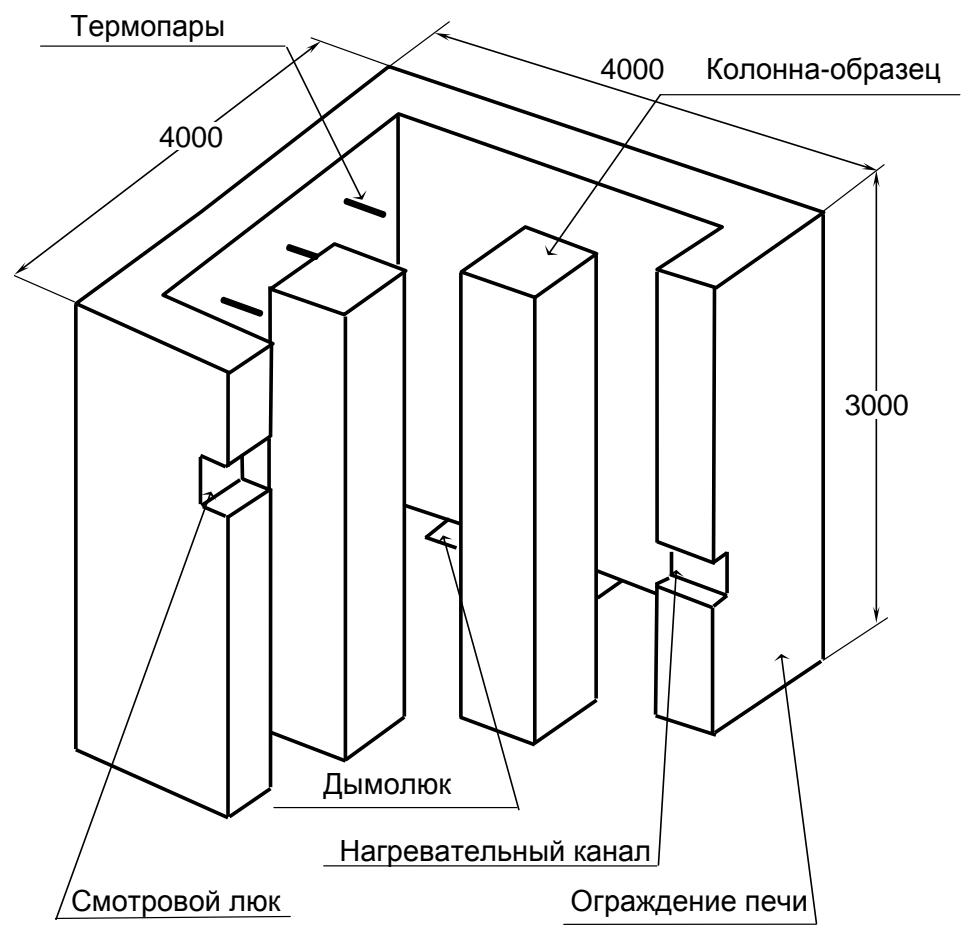

Рис. 3. Схема испытательной установки 


\section{Будівельні матеріали та конструкції}
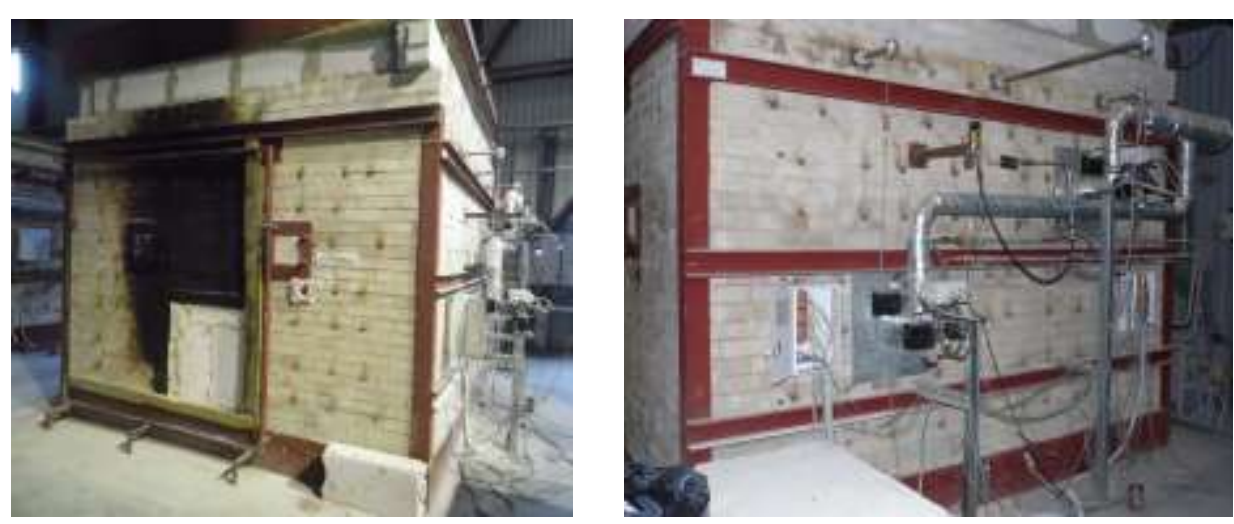

Рис. 4. Общий вид испытательной установки

Схема армирования колонны и схема расположения термопар показаны на рис. 5.

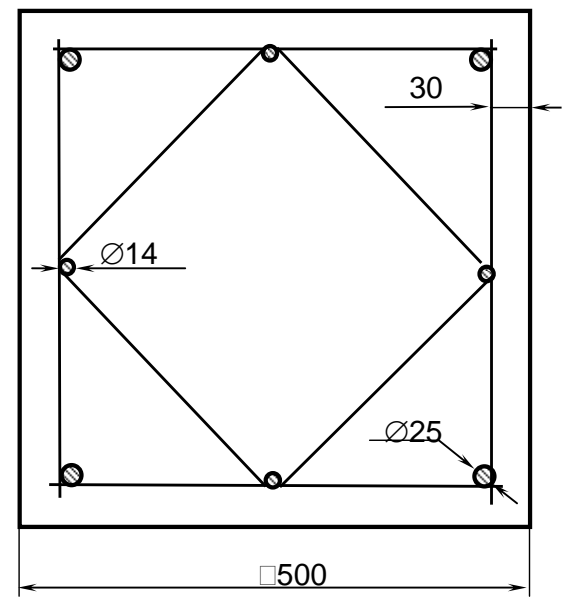

a.

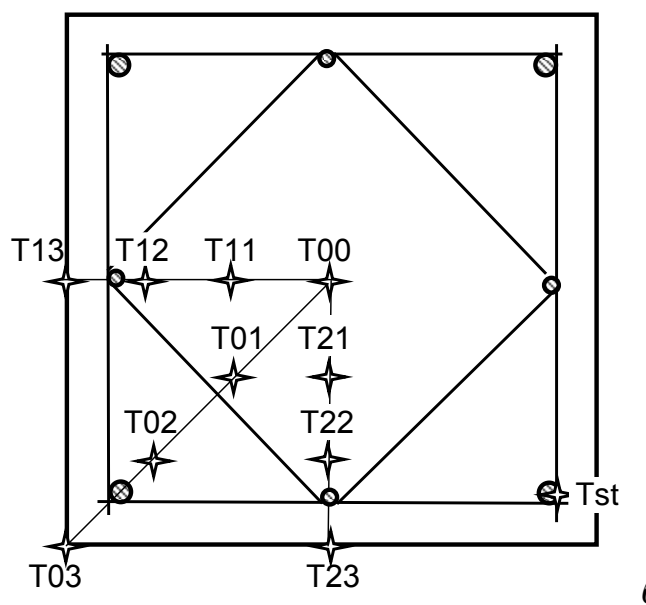

б.

Рис. 5. Схема армирования (а) и схема расположения термопар (б) железобетонной колонны

На рис. 6 показан общий вид образцов перед испытаниями.
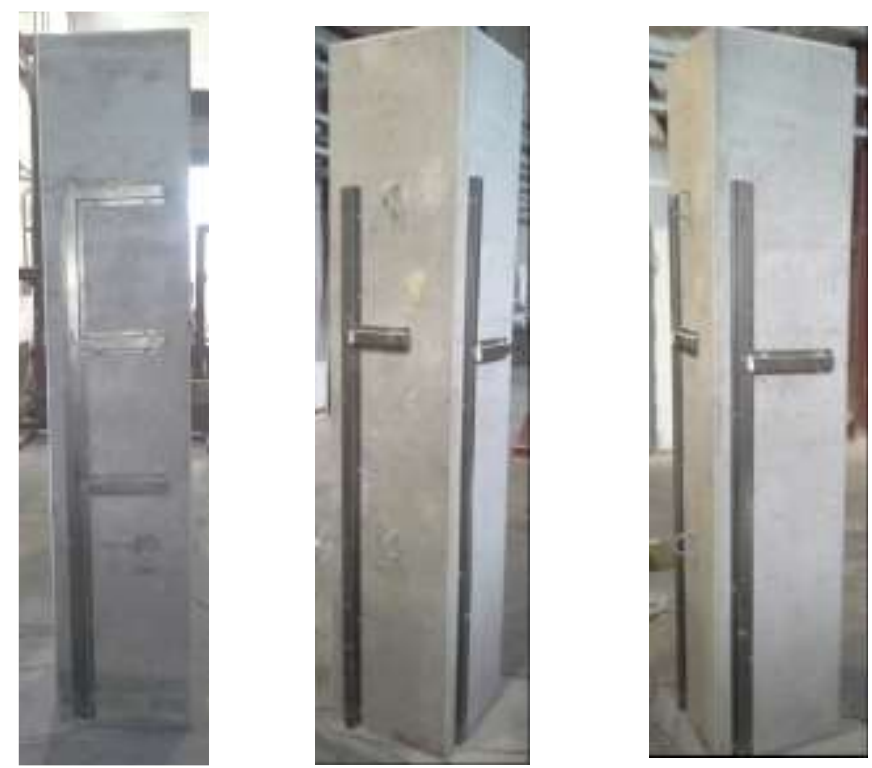

Рис. 6. Общий вид образцов перед испытаниями 


\section{Будівельні матеріали та конструкції}

На рис. 7 показан температурный режим испытаний железобетонных колонн.

Температурные показатели во внутренних слоях сечения колонны показаны на рис. 8.

Используя разработанные алгоритмы, были получены параболические распределения температур в сечении в соответствии с теоретическими представлениями о теплопередаче в железобетонных конструкциях. На рис. 9 представлены результаты расчета по первому и третьему способам. Второй способ дал результаты, которые не сообразуются с теоретическими представлениями о теплопередаче, поэтому в данной статье результаты расчета с его применением не представлены.

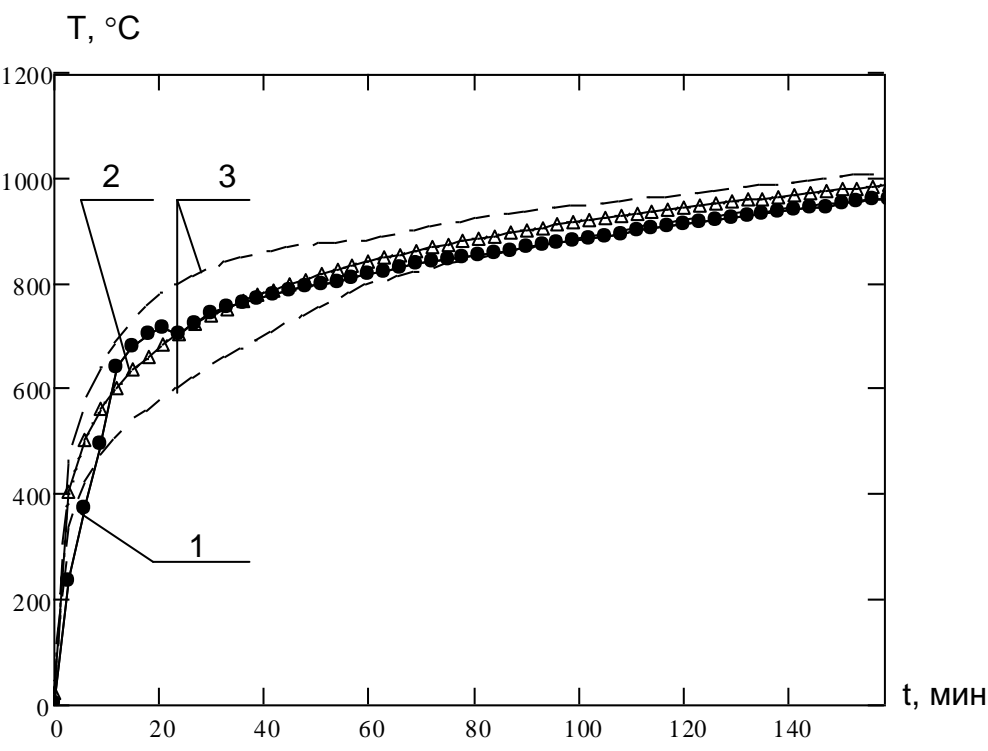

Рис. 7. Температурный режим испытаний в печи:

1 - средняя температура в печи; 2 - стандартная температурная кривая;

3 - допустимые отклонения температурного режима
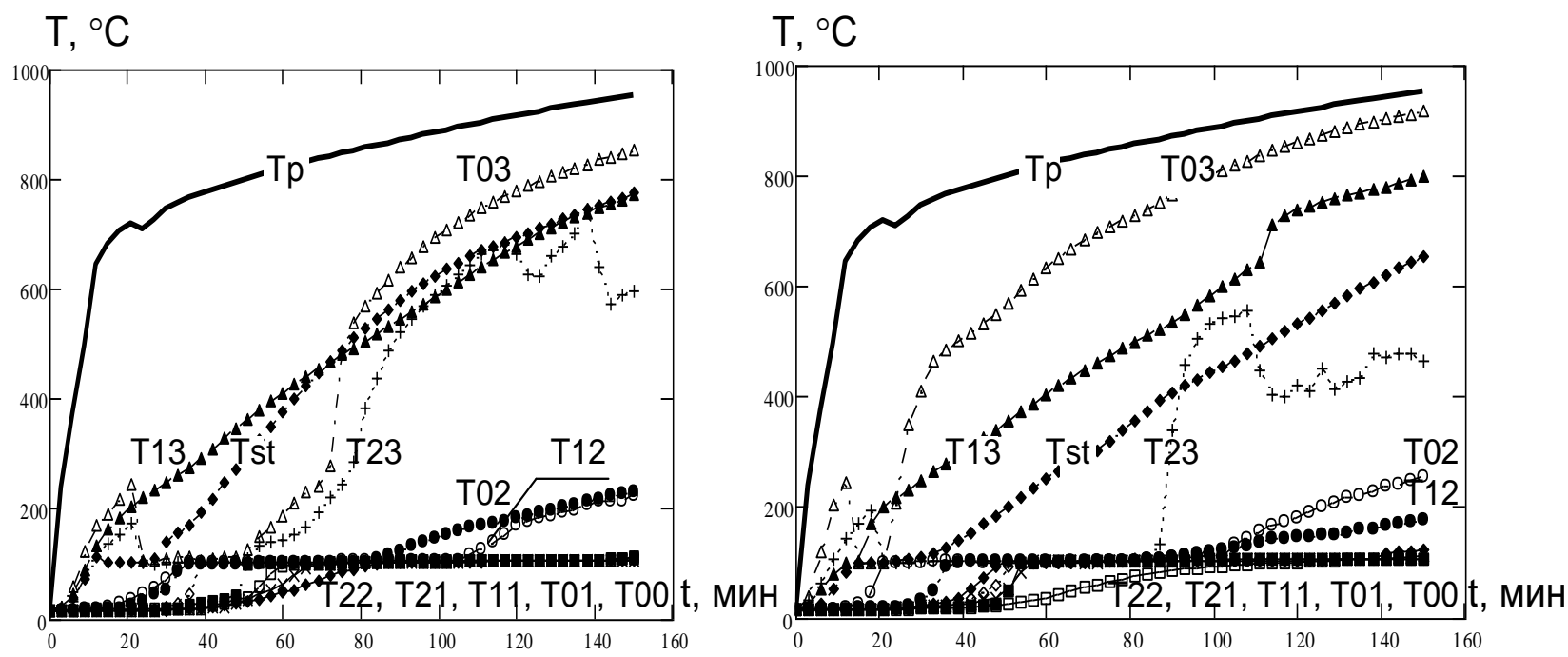

Рис. 8. Результаты измерения температур в колонне 
При сравнении результатов, полученных данными методами, видно, что они подобны. Первый способ позволяет учесть неоднородность огневого воздействия, а второй менее восприимчив к случайным воздействиям в эксперименте типа чрезмерного парообразования из-за плохой сушки колонн-образцов. Для более подробного анализа были рассмотрены отклонения расчетных данных от результатов экспериментов. В таблице приведены результаты проведенного сравнительного анализа.
Первый способ
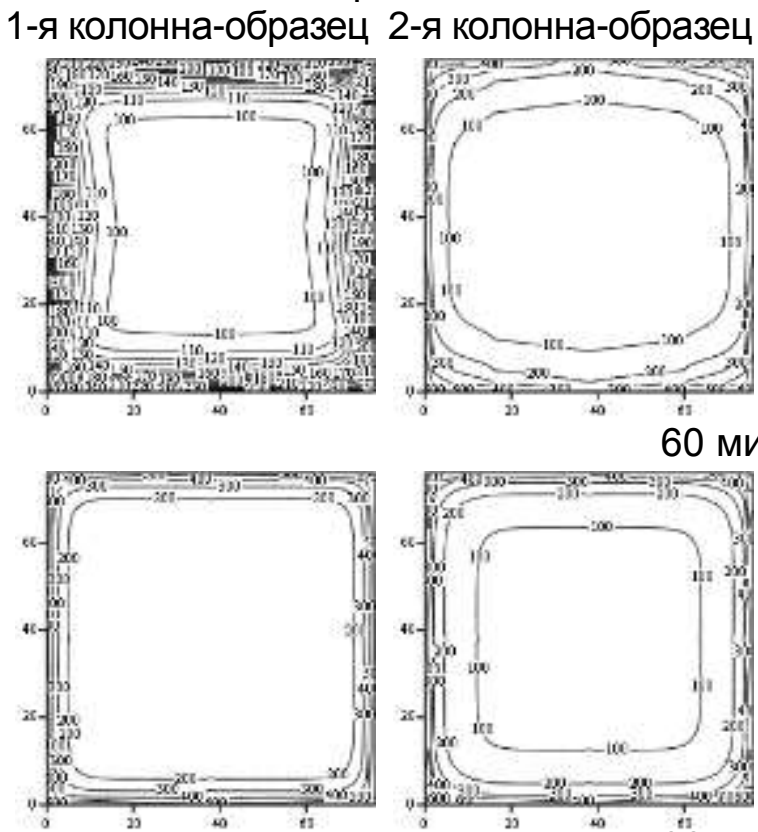

60 мин
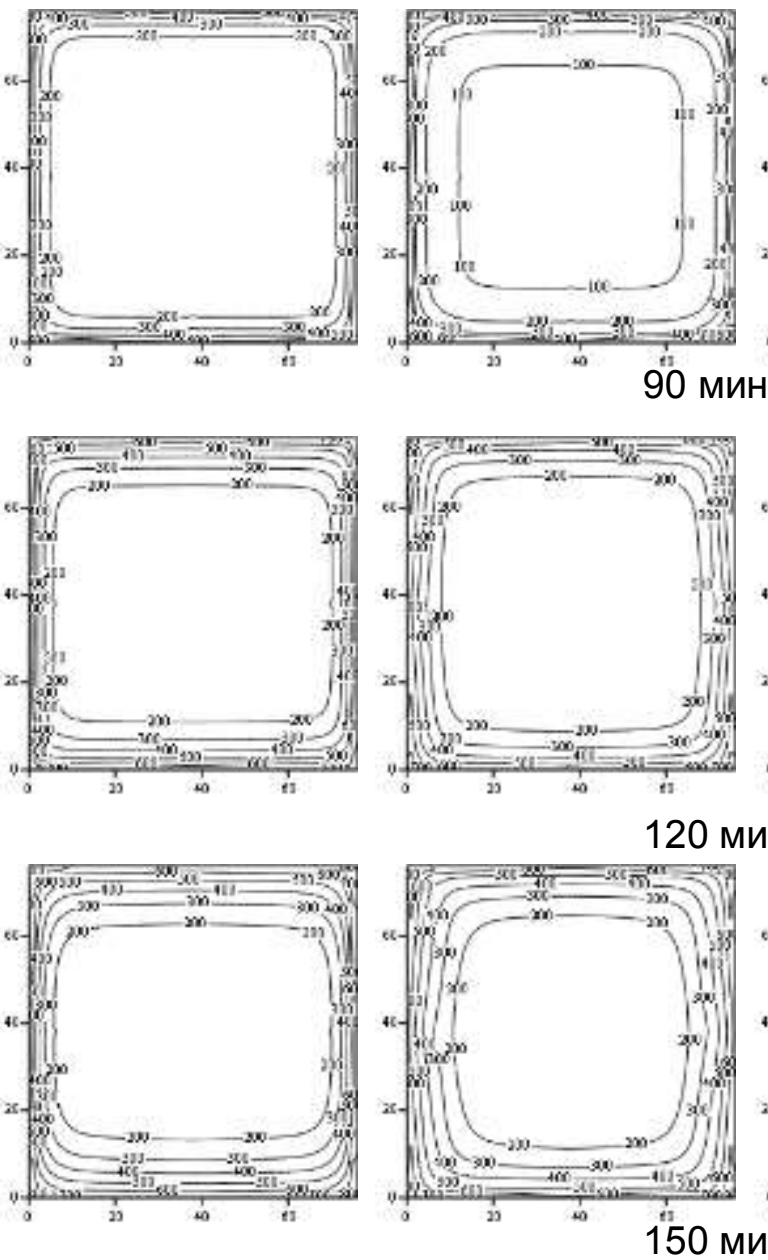
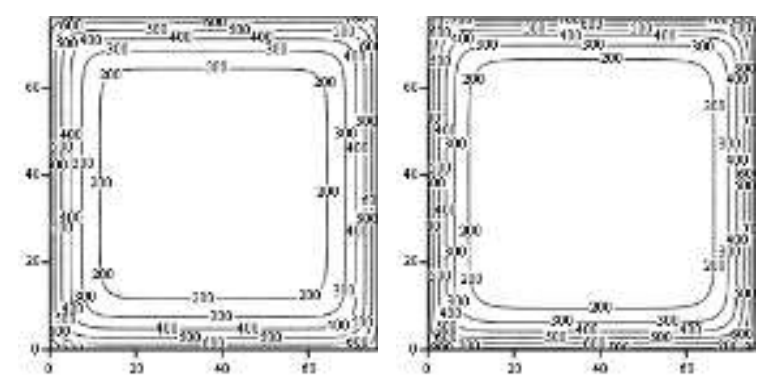

Третий способ
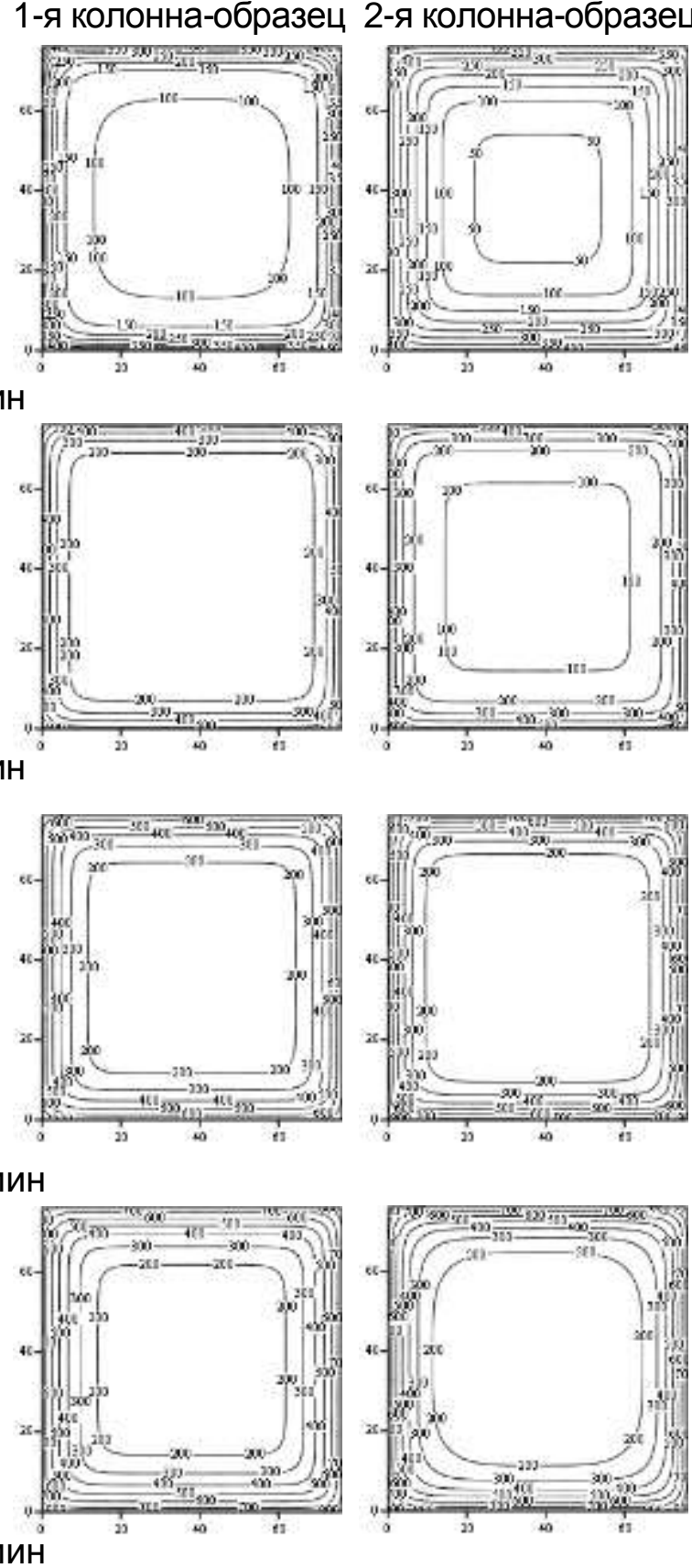

Рис. 9. Результаты измерения температур, ${ }^{\circ} \mathrm{C}$ в колонне 
Таблица

Данные сравнительного анализа результатов интерполяции по разным методам

\begin{tabular}{|c|c|c|c|}
\hline $\begin{array}{c}\text { Способ } \\
\text { интерполяции }\end{array}$ & $\begin{array}{c}\text { Максимальное } \\
\text { отклонение, }{ }^{\circ} \mathrm{C}\end{array}$ & $\begin{array}{c}\text { Среднее относительное } \\
\text { отклонение, } \%\end{array}$ & $\begin{array}{c}\text { Среднеквадратичное } \\
\text { оклонение, }{ }^{\circ} \mathrm{C}\end{array}$ \\
\hline Первый метод & 75 & 7,8 & 26,3 \\
\hline Третий метод & 89 & 6,5 & 25,5 \\
\hline
\end{tabular}

Полученные

результаты интерполяции являются адекватными и их можно использовать для расчета предела огнестойкости согласно одному из методов анализа прочностной задачи. В качестве такого метода предлагается использовать рекомендации евронорм Eurocode 2 [5] пункта В3 дополнения В. Используя данный алгоритм расчета, был построен график критической силы в каждый момент времени испытания. При ее сравнении с действующей силой согласно расчетной схеме конструкции было выявлено, что предел огнестойкости не наступает. На рис. 10 приведены построенные графики.

a)
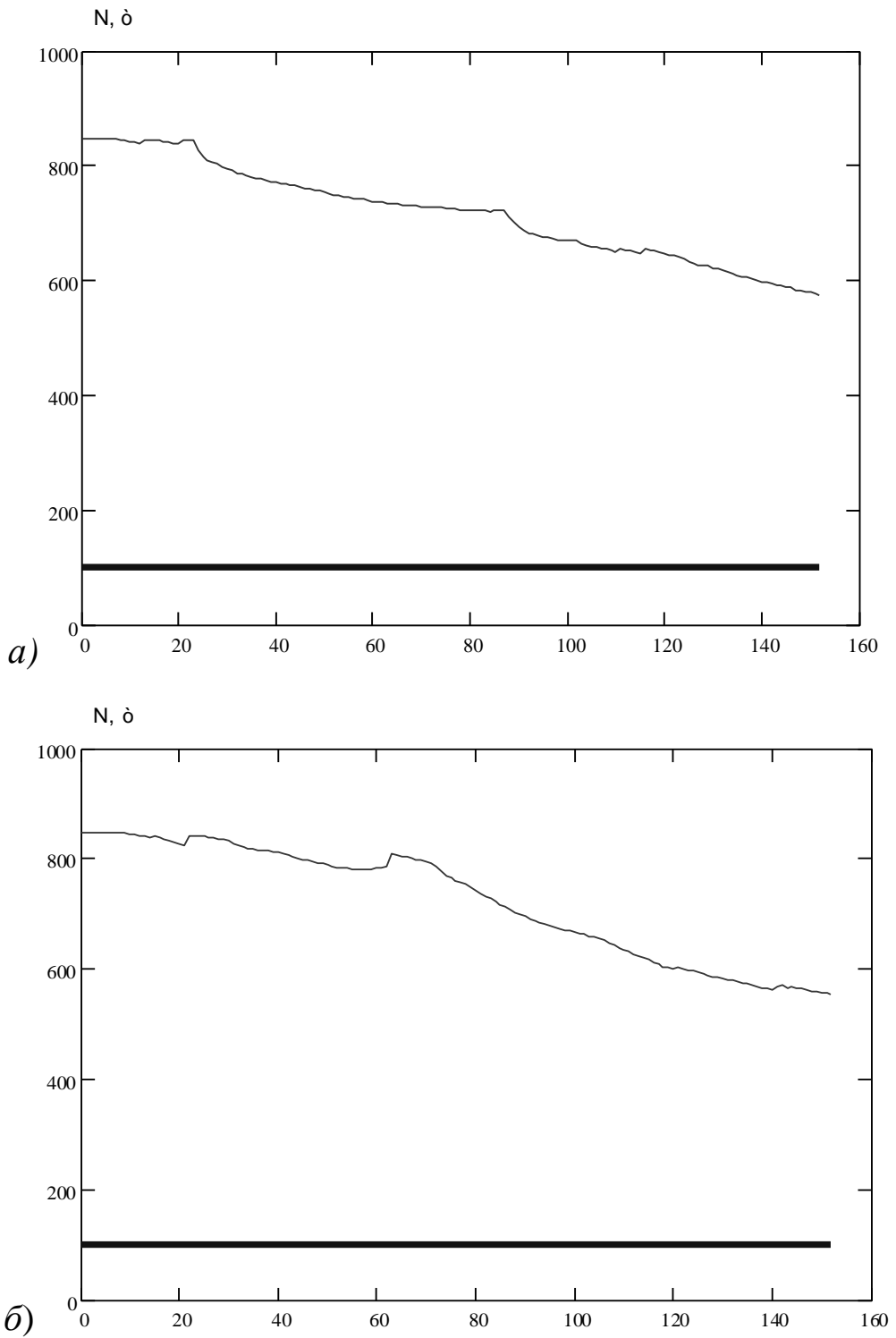

Рис. 10. Несущая способность колонны-образца №1 (а) и колонны-образца №2 (б) 


\section{Выводы}

1. В результате проведенных исследований был разработан экспериментальнорасчетный метод оценки огнестойкости железобетонных колонн на основе их огневых испытаний без приложения механической нагрузки.

2. Разработаны эффективные способы интерполяци для приближения температурных полей в сечениях железобетонных колонн при их огневых испытаниях по данным температурных измерений во внутренних слоях испытуемых колонн.

3. Исследована адекватность результатов, полученных при расчете. Показано, что они являются адекватными для определения предела огнестойкости железобетонных колонн, при этом выделены наиболее эффективные способы интерполяции.

4. Проведены огневые испытания железобетонных колонн и на их основе исследована устойчивость методов интерполяции, в результате чего выделен наиболее эффективный метод итерполяции, который основан на аппроксимации изотерм поля.

5. На основе интерпретации полученных данных в ходе огневых испытаний был определен предел огнестойкости железобетонной колонны, показывающий эффективность разработанного метода.

\section{Список использованной литературы}

1. Захист від пожежі. Пожежна безпека об'єктів будівництва [Текст]: ДБН В.1.1-7-2002. - [Чинний від 2003-05-01]. - К.: Видавництво «Лібра», 2003. - 87 с. - (Національний стандарт України).

2. ДСТУ Б В.1.1-14-98. Захист від пожежі. Колони. Метод випробування на вогнестійкість [Текст]. - К.: Укрархбудінформ, 2005.

3. ДСТУ Б В.1.1-4-98. Будівельні конструкції. Методи випробувань на вогнестійкість. Загальні вимоги. Пожежна безпека [Текст]. - К.: Укрархбудінформ, 2005.

4. Метод інтерпретації результатів вогневих випробувань залізобетонних колон для оцінки їх вогнестійкості [Текст] / С.В. Поздєєв, I.P. Василенко, О.Г. Кузьмін, В.К. Словінський // Матеріали 15 Всеукраїнської науково-практичної конференції рятувальників. - К.: Інститут державного управління у сфері цивільного захисту, 2013. C. 25-26.

5. EN 1992-1-2:2004 Eurocode 2: Design of concrete structures Part 1-2: General rules Structural fire design, Brussels, 2004.

6. Милованов, А.Ф. Огнестойкость железобетонных конструкций [Текст] / А.Ф. Милованов. - М.: Стройиздат, 1986. - 224 с.

7. Исследование эффективности математических моделей для решения теплотехнической задачи при определении огнестойкости железобетонных конструкций / С.В. Поздєєв, В.Г. Поклонский, О.В. Некора, А.В. Поздеев // Строительство, материаловедение, машиностроение : сб. науч. трудов. - Днепропетровск: ПГАСА, 2010. Вып. 52: серия «Безопасность жизнедеятельности. - С. 44-48.

Рецензент д-р техн. наук, профессор А.А. Плугин

Поздеев Сергей Валерьевич, доктор технических наук, доцент, начальник кафедры строительных конструкций Академии пожарной безопасности имени Героев Чернобыля. Контактный тел. 0452 -55-09-41 (2-77).

Словинский Виталий Казимирович, старший преподаватель кафедры оперативно-тактической деятельности Академии пожарной безопасности имени Героев Чернобыля. Контактный тел. 0452 -55-09-41 (2-67). 


\section{Будівельні матеріали та конструкції}

Омельченко Андрей Николаевич, инспектор, Главное управление Государственной службы по чрезвычайным ситуациям Украины в Киевской области. Контактный тел. 0452 -55-09-41 (2-77)

Кропива Михаил Александрович, адъюнкт дневной формы Академии пожарной безопасности имени Героев Чернобыля.

Pozdeyev Sergey, doct. of techn. sciences, associate professor chief of department of build structures The Academy of Fire Safety named after Chernobyl Heroes. Contact tel. 0452 -55-09-41 (2-77)

Slovinskiy Vitaliy, teacher of department of operative-tactical activity The Academy of Fire Safety named after Chernobyl Heroes. Contact tel. 0452 -55-09-41 (2-67)

Omelchenko Andrey, inspector, Main administration of Government service on the extraordinary situations of Ukraine in the Kiev region. Contact tel. 0452 -55-09-41 (2-77)

Kropiva Michail, adjunct of daily form The Academy of Fire Safety named after Chernobyl Heroes. 